grams, phonocardiograms and angiocardiograms.

One noteworthy feature is the chapter on constitution and diathesis, subjects seldom considered in English textbooks. The relationship between external appearance and character and predisposition to disease is a subject that fascinates, even if it does not always convince. Special mention must be made of the excellent chapter on tuberculosis by Professor Wallgren.

The illustrations in 'Grulee and Eley' are good; the even more numerous illustrations in 'Fanconi and Walgren' are superlatively good. In particular the colour photographs of skin diseases are the best the reviewer has ever seen. This excellence is partly due to the superior paper and partly to the use of full-plate reproductions; perhaps this also accounts for the added expense of the book.

The reviewer was rather surprised to find few differences in outlook between American and Continental paediatricians on subjects of major importance. An exception may be found on pages 27 of 'Grulee and Eley' and 74 of 'Fanconi and Wallgren,' which read respectively, 'There are only a few things which a child must do, and only a very few he should not do. The most efficacious way of slowly teaching children these few restrictions is by placing them in their play pen or play room when their behaviour is too disturbing or overly destructive, and thus curtailing their freedom. This can be done without anger on the part of the parents or stimulation of fear in the mind of the child; it is the only form of force that is necessary' and 'The child must be introduced into the society of other children. To overcome his egocentric attitude it is generally necessary to use more or less severe methods of punishment, such as a rap on the fingers.'

Perhaps this shows that on the subject of rearing normal children there is more divergence of opinion than on most other paediatric problems!

The senior student, general practitioner or paediatrician who wishes to buy a textbook of advanced paediatrics can be advised confidently that 'Grulee and Eley' is the equal of the other textbooks mentioned. ' Fanconi and Wallgren' can be equally confidently recommended as bedtime reading for the more experienced paediatrician in the certainty that it will provide him with much useful and sometimes unusual information, as well as entertainment. Both books should be in every medical library.

\section{MORBUS ALHZEIMER AND MORBUS PICK}

By T. SJögren, H. Sjögren and $\stackrel{\circ}{A}$. G. H. LiNDGREN. Pp. 1 52, illustrated. Copenhagen: Ejnar Munksgaard. 1952.

This erudite genetic, clinical and pathoanatomical study is only for advanced students of genetics, psychiatry, neurology and neuropathology, and to them it is commended.

J.D.W.P.
A TEXTBOOK OF MENTAL DEFICIENCY (AMENTIA)

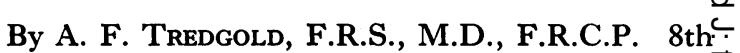
Edition. Pp. xvi +546 , with 48 illustrations. $\overrightarrow{\bar{F}}$ London: Ballière, Tindall and Cox. 1952 37s. $6 \mathrm{~d}$.

The medical textbooks published in the 2oth $\frac{\overline{\bar{c}}}{\overline{\frac{\sigma}{2}}}$ century which have earned for themselves a world-ब wide reputation are few in number. Tredgold' $s_{0}$ mental deficiency takes a leading place in that ${ }^{(s)}$ select few. The appearance of the eighth edition $\overrightarrow{0}$ reminds us that the first appeared as far back asr 908 and that the new edition made its appearance $\vec{\omega}$ the day before the death of its distinguished author. His son, Dr. R. F. Tredgold, has assisted in theo preparation of this edition and it is to be hoped that 3 the future of the work may be assured for manyig years to come.

Tredgold's textbook has for long been the essential textbook in English for all those needingi up-to-date information and authoritative discussion 0 on the causes, clinical types and treatment of mental defectives. This new edition remains up to date응 while preserving its author's cautious attitude torecent work on etiology or treatment which may not $>$ yet be fully confirmed by parallel clinical research or을 experience.

The clinical sections of the book are well knophif for their excellence. They are often dramatic in their clarity of description; an example is to tersely phrased paragraph which describes absolutte or complete idiocy. These sections are well illustrated by plates (some of which are new) and by many descriptive cases. The discussion of the $\frac{\circ}{\mathbb{2}}$ clinical types is thorough and presents the latest views on pathology and treatment. The rarities are $\overrightarrow{\vec{O}}$ all there and in this respect it can be recorded that 3 the book contains an admirable index which functioned accurately on every occasion it was wantedo by the reviewer. As a work of reference the clinical sections are unsurpassed.

The chapter on aetiology shows considerable $\overline{0}$ change and contains references to recent work on? ante-natal pathology as a cause of defect. In the $\delta$ discussion on what are often called 'stressing agents' acting during pregnancy the author refers $\mathrm{O}$ to Gregg's clinical work on the effects of maternal rubella during the early months of pregnancy. $\mathrm{He}$ ? also refers to the work of experimental embryologists, such as Warkany and Hale, on the dire N effects of lack of vitamin A during pregnancy. There is no mention of the interesting work of $N$ Ingalls and his co-workers on the results of maternal anoxia during pregnancy on the offspring of mice, $O$ work which opens up new fields of study in causation and therefore prevention. In this chapter on aetiology expert medical readers may like to know more of the author's claim to have seen cases in which the prolonged use of a soluble contraceptive ${ }^{T}$ pessary has failed and been followed by the birth $\frac{+}{+}$ of a defective child. The claim is sure to have been $\stackrel{\oplus}{\stackrel{P}{9}}$ 
based on clinical observation and Dr. Tredgold has been careful to insist that ' our knowledge of antenatal pathology is still limited.'

In the chapter on moral deficiency the author deals with one of the four classes defined by the Mental Deficiency Act-the moral defective-a conception which has caused so much difficulty to doctors, students and administrators. This chapter clarifies the various possibilities in diagnosis that arise when the doctor is presented with a juvenile delinquent. The author does conclude that there is a rare class of case which shows moral defect due to 'a defect of mind which is permanent and incurable.' He points out that many so-called moral defectives have acquired a wrong label and that misconduct or delinquency has, in fact, arisen from environmental or psychological causes. Dr. Tredgold approves of the juvenile court, the guidance clinics or departments of child psychiatry and of the work of psychiatrists in prisons. It is his opinion that the extension of such facilities will eventually produce a diminution in crime "provided they are kept on sane and proper lines and are not allowed to develop into sentimental fads.' Every experienced psychiatrist will welcome these words.

The legal relations of mental deficiency are dealt with so that the enquirer can ,find readily the answers to his queries, be they medical or administrative. Mental deficiency and Education Acts are brought up to date and there is a clear section on educationally subnormal children which contains the famous follow up of 9,218 such children passing through the special schools of the City of Birmingham.

The chapter on the social implications of mental deficiency and what it may mean to civilized communities should be read and digested by everyone with an interest in the future of civilized countries. It contains a reasoned plea for the development of a social sentiment or conscience concerning marriage and reproduction by the diseased, the degenerate, the chronic criminal and the habitual pauper. Dr. Tredgold points out that it is to an informed medical profession that the State and the public must look for guidance and advice.

Tredgold's work should be possessed by every doctor. It is a necessity to the medical student and the graduate taking a higher qualification in psychiatry. Intelligent lay people with an interest in sociology will find it an extremely useful book of reference. It is a work closely packed with learning, the gathering of a long and busy life.

It would be unkind not to mention the publishers, Messrs. Ballière, Tindall and Cox, and to offer them an expression of sympathy on the close of a long and successful association with a great medical 'teacher and author. This edition is beautifully printed and bound. Although it contains more pages the book is actually less bulky than the reviewer's well-thumbed fifth edition.

G.W.B.J.

\section{ANATOMY OF THE AUTONOMIC NERVOUS SYSTEM}

By G. A. G. Mitchell, O.B.E., T.D., M.B., Ch.M., D.Sc. Pp. xvi +356 , with $\mathrm{r}_{3} \mathrm{r}$ illustrations, many in colour. Edinburgh: E. \& S. Livingstone Ltd. 1953. 55 s.

In this book, which, as the author states in his preface, is "primarily anatomical and concerned with man,' the word 'autonomic' is interpreted very broadly, and the field covered is correspondingly extensive. The first four chapters contain a historical survey and general accounts of the terminology, development and histology of autonomic nervous structures; they are followed by an account of certain regions of the central nervous system which may be concerned in autonomic function, including a description of the frontal lobes of the brain and their connexions, and a detailed summary of our present knowledge of the structural features of the hypothalamus. The remaining chapters, which form rather more than half of the book, are taken up with a description of the peripheral distribution of the sympathetic and parasympathetic nerves and plexuses. The illustrations are numerous and practically without exception of a very high standard. A full bibliography is given which will be of great value to those who wish to carry their studies further than is possible within the confines of a single volume.

Among the varied topics discussed two, at least, call for special notice. In the earlier chapters the description of the frontal lobes of the brain and of the hypothalamus is based on recent work, much of which has not yet found its way into textbooks. It is scattered in a large number of papers, many from the Oxford School of Anatomy, and in collecting this information together, Professor Mitchell has performed a valuable service to those who have not the time or opportunity to consult-the original publications. In the later chapters, the results of Professor Mitchell's own researches; chiefly on the peripheral autonomic nerves and plexuses, forms the basis of much that is described. To anatomists Professor Mitchell's careful and meticulous work in this difficult field is well known. The fact that so much has been checked, or in some cases recorded for the first time, as a result of the author's personal observations on human material, gives these chapters an authority which is not often found in similar descriptions. The work on which they are based is a substantial contribution to knowledge, and it is pleasant to find it so clearly described and illustrated in a single volume which will be easily accessible.

As was said, the term 'autonomic' is interpreted very broadly and one cannot escape the feeling that some of the less satisfactory features of the book are a result of this. Langley's original and precise definition, as an efferent system to visceral structures, consisting of pre- and post-ganglionic neurones connected by a synapse outside the central 